\title{
Theory and experimental research on spiral bevel gear by double-side milling method
}

\author{
Longlong Geng ${ }^{1}$, Xiaozhong Deng ${ }^{2,}{ }^{*}$, Hua Zhang ${ }^{3}$, Shaowu $\mathrm{Nie}^{3}$, and Chuang Jiang ${ }^{3}$ \\ ${ }^{1}$ School of Mechatronic Engineering, Northwestern Polytechnical University, 127 Youyi West Road, Xi'an 710072, PR China \\ 2 Collaborative Innovation Center of Machinery Equipment Advanced Manufacturing, Henan Province, 48 Xiyuan Road, \\ Luoyang 471003, PR China \\ 3 School of Mechatronics Engineering, Henan University of Science and Technology, 48 Xiyuan Road, Luoyang 471003, \\ PR China
}

Received: 2 October 2020 / Accepted: 12 April 2021

\begin{abstract}
In this paper, a double-side milling method on spiral bevel gear is proposed. First, according to the tooth taper processed by double-side milling method, the influence of dedendum angle on the tooth taper was researched. Taking cut parameters into comprehensive consideration, the geometric parameters were designed through the inclination of root line and modified mean point in which machine setting parameters calculated was selected. Only the modified mean point met the meshing equation, and the error of pressure angle would increase as far away from the modified mean point in tooth line. The error would lead to bias in contact. A helical correction motion was introduced and the influence of helical motion coefficient on tooth surface topology was studied. Based on the meshing performance, a suitable coefficient was calculated. Finally, an example was illustrated. The experimental results were consistent with the theoretical analysis. The validity of the proposed method is verified.
\end{abstract}

Keywords: Spiral bevel gear / double-side milling method / geometric parameter design / modified mean point / helical motion / cutting experiment

\section{Introduction}

Spiral bevel gear is widely used in aviation, aerospace, marine and machine tool for its advantages of driving smoothly, high transmission efficiency, excellent load capacity, etc. Therefore, the manufacturing of spiral bevel gear has been an important topic. Many experts and scholars have carried out deeply research. The mainly machining methods for spiral bevel gear are face-milling and face hobbing.

For face milling, according to machine method of pinion can be divided into five-cut and two-cut. Generalized theory and methods of spiral bevel and hypoid gears manufactured by the five-cut method have been comprehensively presented by several gear scientists [1-3]. Shtipelman [4] introduced the generalized theory of the five-cut method and calculated machine settings parameters of spiral bevel and hypoid gears by the five-cut method in Gleason Works. Litvin [5,6] proposed local synthesis and applied for tooth contact analysis (TCA),

\footnotetext{
* e-mail: dxz01@163.com
}

and determining the optimal machine settings parameters. For five-cut, the concave side and convex side adopts different machine setting parameters which the mesh performance can effectively control and correction.

In Gleason technology, two-cut method includes duplex spread blade method and duplex helical method. Traditionally, duplex spread blade method is used to process small module of spiral bevel gear. In book of spiral bevel gears published by Beijing gear factory proposed the calculation of machine setting parameters by duplex spread blade method, but its principle is not revealed [7]. K. Kawasaki and H. Tamura [8] proposed a method to manufacture gear with a large radius of curvature cutting edge and a modified tooth surface is obtained. Recently, Deng et al. [9] proposed a method to manufacture spiral bevel gear by duplex spread blade method and the mesh performance is optimized by tooth surface modification.

Duplex helix method is fist put forward by Gleason [10], but principle and calculation of machine setting parameters are not revealed. Tsay and Lin [11] developed a mathematical model can be applied to simulate tooth surface geometry machined by duplex spread blade and 
duplex helical method. Gonzalez-Perez [12] approached conversion of the specific machine settings parameters of a given generator to neutral machine-tool setting by duplex heliacal method, and parabolic profile on the blades of the head cutter was applied to adjust the contact pattern. Zhang et al. [13,14] revealed the generalized theory of helical method in which gear was non-generated and calculated the basic machine settings parameters by define three reference points. However, the calculation of machine setting parameters by duplex helix method is complicated, and the requirements for the machine are harsh. It is difficult to control and correct mesh performance for concave side and convex side are processed by same machine setting parameters.

In this paper, a double-side milling method to machine spiral bevel gear is proposed which the calculation of machine setting parameters is simple. Through inclination of root line and considering cut parameters, geometrical parameters are designed by double-side milling method. In order to guarantee the normal tooth meshing, a modified mean point is selected, and machine setting parameters are calculated in modified mean point. Aiming at optimize the bias in contact caused by cut number; a helical motion is introduced to modify the pressure angle on the pitch line. Contact performance is controlled by adjusting coefficient of helical motion.

\section{Geometric parameter design}

\subsection{Tooth taper}

The taper of tooth blank is different from single-side method to double-side method. Dedendum angle will affect tooth height in the direction of tooth length from toe to heel, and the influence of dedendum angle on tooth taper are analyzed as follow.

In single-side method, tooth height and tooth thickness are proportional to cone distance, as shown in Figure 1a. A tangent angle formed at mean point $P_{a}$ on both sides of tooth space $P_{a 1} P_{a 2}$ can be expressed as

$$
\angle P_{a 1} O_{a} P_{a 2}=\frac{\widehat{p_{a 1} p_{a 2}}}{s}
$$

Here $s$ is the mean point arc tooth thickness of paired gear.

While for double-side method, two sides of tooth surface are processed simultaneously by double-side cut. The tooth lines on both sides are concentric arcs, as shown in Figure 1b. Then the tangent angle formed at mean point $P_{b}$ on both sides of tooth space $P_{b 1} P_{b 2}$ can be expressed as

$$
\angle P_{b 1} O P_{b 2} \approx \frac{s \sin \beta}{r}
$$

Here $O$ is the center of cut, and $r$ is the nominal radius of cut, $\beta$ is mean spiral angle.

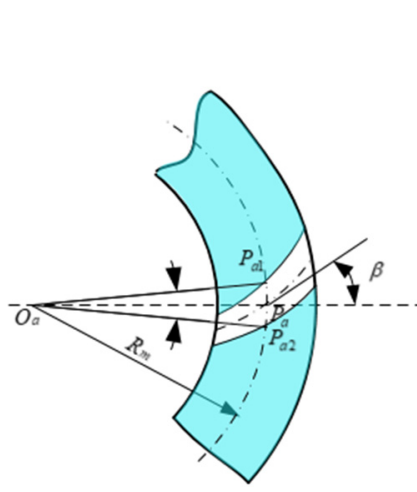

(a)

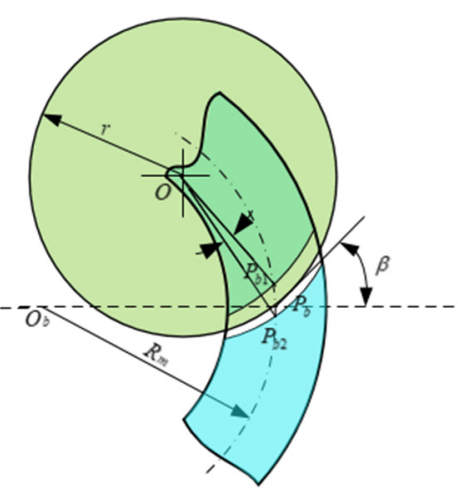

(b)
Fig. 1. Flank lines on the pitch cone. (a) Tooth blank in singleside method. (b) Tooth blank in double-side method.

Comparing Figure 1, a difference of tangent angle occurs and can be expressed as

$$
\Delta \psi_{1}=\angle P_{a 1} O_{a} P_{a 2}-\angle P_{b 1} O P_{b 2}=\frac{s}{R_{m}}\left(1-\frac{R_{m} \sin \beta}{r}\right)
$$

Here $R_{m}$ is mean cone distance.

The axis of cut is perpendicular to the root cone of tooth blank during manufacturing. So the outer of tooth blank will be cut more deeply than the inner and the tangent angle formed at mean point on both sides of tooth space can be increased which will make up for $\Delta \psi_{1}$.

In order to research the influence of dedendum angle on $\Delta \psi_{1}$, another point $p^{\prime}$ was taken near the tooth line, and the position of point was: $\Delta R$ in the direction of cone distance, $\Delta h$ in the direction of tooth height, and $\Delta s$ the difference of tooth space width. The distance between the two points was $\Delta L$, as shown in Figure 2. The increment of tangent angle on tooth line can be expressed as:

$$
\Delta \psi_{2} \approx \tan \Delta \psi_{2}=\frac{\Delta s}{\Delta L}=2 \tan \theta_{f} \tan \alpha \cos \beta
$$

Here $\alpha$ is nominal pressure angle.

If $\Delta \psi_{1} \neq \Delta \psi 2$, it may cause abnormal tooth taper using double-side method, which will seriously affect the strength and cut life. So this situation should be avoided.

There are many factors affect $\Delta \psi_{1}$ and $\Delta \psi_{2}$ from equations (3) and (4). But some parameters should not be changed after determined. So dedendum angle $\theta_{f}$ is changed to meet the requirements $\Delta \psi_{1}=\Delta \psi_{2}$. Finally, an ideal dedendum angle can be calculated as

$$
\theta_{f} \approx \tan \theta_{f}=\frac{s}{2 R_{m} \tan \alpha \cos \beta}\left(1-\frac{R_{m} \sin \beta}{r}\right)
$$

The above analysis is suitable for pinion and gear. If both machined by double-side method, the following relationship can be obtained

$$
\sum \theta_{D}=\theta_{f 1}+\theta_{f 2}=\frac{s_{1}+s_{2}}{2 R_{m} \tan \alpha \cos \beta}\left(1-\frac{R_{m} \sin \beta}{r}\right)
$$




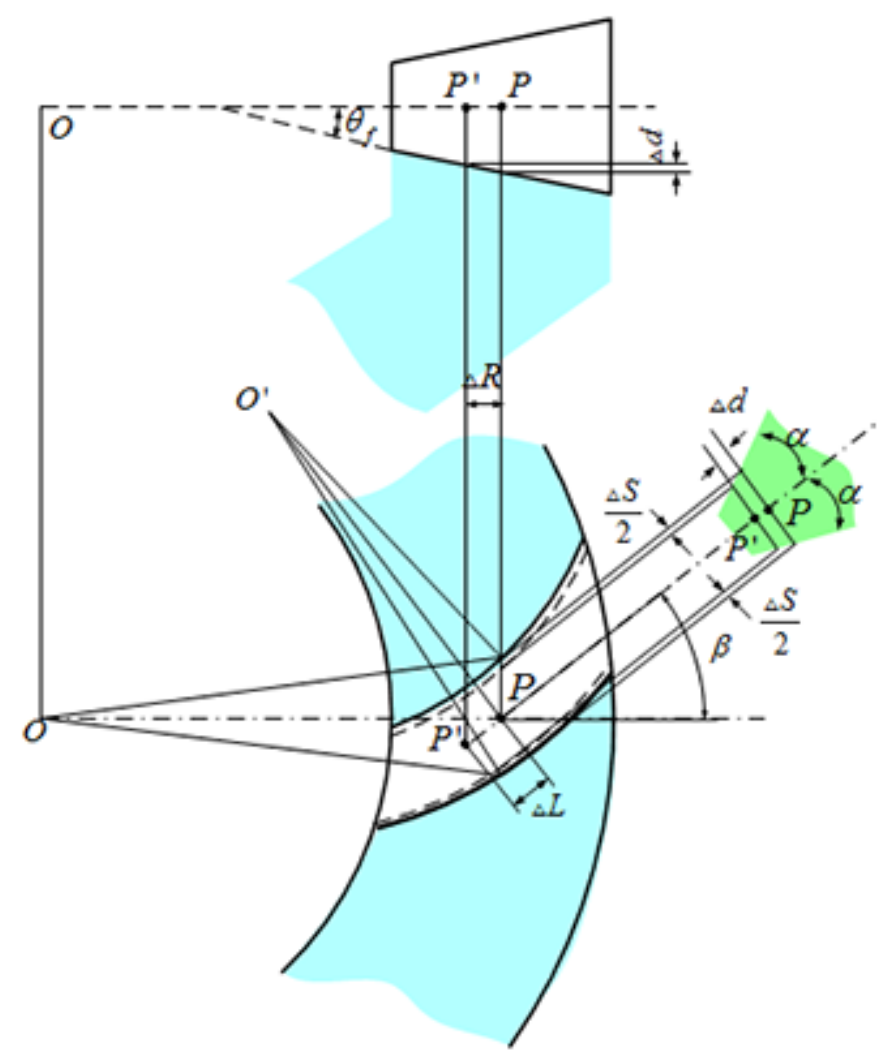

Fig. 2. Effect of dedendum angle on tooth taper.

Here $\theta_{f 1}, \theta_{f 2}$ are dedendum angle of pinion and gear respectively; $s_{1}, s_{2}$ are the mean point arc tooth thickness, and meet $z_{0}\left(s_{1}+s_{2}\right)=2 \pi R_{m}, z_{0}$ is the equivalent number of crown teeth.

Then equation (6) can be expressed as

$$
\sum \theta_{D}=\frac{\pi}{z_{0} \tan \alpha \cos \beta}\left(1-\frac{R_{m} \sin \beta}{r}\right)
$$

Assuming sum of standard depth dedendum angle $\sum \theta_{s}$ satisfying the condition $\Delta \psi_{1}=\Delta \psi_{2}$, then a nominal radius of cut can be obtained from Equations (3) and (4)

$$
r=R_{m} \sin \beta /\left(1-\frac{\sum \theta_{s} z_{0} \tan \alpha \cos \beta}{180}\right)
$$

Then a nominal radius $r_{c}$ can be selected according to equation (8), Substituting $r_{c}$ into equation (7), the corresponding sum of dedendum angle $\sum \theta_{T}$ can be expressed as

$$
\sum \theta_{T}=\frac{\pi}{z_{0} \tan \alpha \cos \beta}\left(1-\frac{R_{m} \sin \beta}{r_{c}}\right)
$$

The nominal radius $r_{c}$ will affect sum of dedendum angle $\sum \theta_{T}$ and flank taper. In order to avoid excessive taper of tooth blank caused by difference of nominal radius between calculated and selected, the recommended range of nominal radius is $1.1 R_{m} \sin \beta \leq r_{c} \leq R_{m}$.

\subsection{Geometric parameter design}

Different from the traditional method of calculating geometric parameters by outer transverse module in heel, the double-side geometric parameter design of spiral bevel gear is completed by mean normal module. In order to ensure the proper meshing depth of tooth at the mean point, mean working depth $h_{m w}$ can be calculated as

$$
\begin{aligned}
& h_{m w}=h m_{n} \\
& m_{n}=\frac{R_{m} m_{t}}{R} \cos \beta
\end{aligned}
$$

Here $h$ is working tooth height factor, $m_{n}$ is normal modulus of mean point, $m_{t}$ is outer transverse module, and $R$ is outer cone distance.

The clearance of spiral bevel gear is calculated according to the mean point and keeps constant in the direction of tooth length. The clearance can be adjusted according to the design requirements and calculated as

$$
c=m_{n} c_{1}
$$

Here $c_{1}$ is clearance factor.

Then mean whole depth can be expressed as

$$
h_{m}=h_{m w}+c
$$

According to mean addendum factor $c_{\text {ham }}$, the mean addendum and mean dedendum can be expressed as

$$
\begin{aligned}
& h_{a m 2}=c_{h a m} h_{m w} \\
& h_{a m 1}=h_{m w}-h_{a m 2} \\
& h_{f m 2}=h_{m}-h_{a m 2} \\
& h_{f m 1}=h_{m}-h_{a m 1}
\end{aligned}
$$

Dedendum angle is distributed according to the ratio of mean dedendum to mean whole depth

$$
\begin{aligned}
& \theta_{f 1}=\frac{h_{a m 2}}{h_{m w}} \sum \theta_{T} \\
& \theta_{f 2}=\sum \theta_{T}-\theta_{f 1}
\end{aligned}
$$

Then theoretical cut number can be calculated as

$$
N=\frac{\sum \theta_{T}}{20} \sin \beta
$$

As cut numbers have been standardized and serialized, so an approaching cut number $N_{0}$ is selected. In order to make up for the difference of real and theoretical cut number, root line is tilted around mean point and the amount of tilt can be expressed as

$$
\Delta \theta_{f}=\frac{10 N_{0}}{\sin \beta}-\frac{\Sigma \theta_{T}}{2}
$$


Finally dedendum angle can be obtained according to equation (14) and (16). The addendum angles can be expressed as

$$
\begin{aligned}
& \theta_{a 1}=\theta_{f 2} \\
& \theta_{a 2}=\theta_{f 1}
\end{aligned}
$$

Above parameters are calculated at mean point. In order to facilitate measurement in production, the above data should be converted to heel.

Face cone angle $\delta_{a 1}, \delta_{a 2}$ can be expressed as

$$
\begin{aligned}
& \delta_{a 1}=\delta_{1}+\theta_{a 1} \\
& \delta_{a 2}=\delta_{2}+\theta_{a 2}
\end{aligned}
$$

Root cone angle $\delta_{f 1}, \delta_{f 2}$ can be expressed as

$$
\begin{aligned}
& \delta_{f 1}=\delta_{1}-\theta_{f 1} \\
& \delta_{f 2}=\delta_{2}-\theta_{f 2}
\end{aligned}
$$

Then outer dedendum and outer addendum can be expressed as

$$
\begin{aligned}
& h_{a e 1}=h_{a m 1}+0.5 b \tan \theta_{a 1} \\
& h_{a e 2}=h_{a m 2}+0.5 b \tan \theta_{a 2} \\
& h_{f e 1}=h_{f m 1}+0.5 b \tan \theta_{f 1} \\
& h_{f e 2}=h_{f m 2}+0.5 b \tan \theta_{f 2}
\end{aligned}
$$

Outer working depth can be expressed as

$$
h_{w e}=h_{a e 1}+h_{a e 2}
$$

Outer whole depth can be expressed as

$$
h_{e}=h_{a e 1}+h_{f e 1}
$$

Outer diameter can be expressed as

$$
\begin{aligned}
& d_{a e 1}=z_{1} m_{t}+2 h_{a e 1} \cos \delta_{1} \\
& d_{a e 2}=z_{2} m_{t}+2 h_{a e 2} \cos \delta_{2}
\end{aligned}
$$

Pitch cone apex to crown can be expressed as

$$
\begin{aligned}
& X_{e 1}=R \cos \delta_{1}-h_{a e 1} \sin \delta_{1} \\
& X_{e 2}=R \cos \delta_{2}-h_{a e 2} \sin \delta_{2}
\end{aligned}
$$

Then geometric parameters of spiral bevel gear can be calculated

\section{Calculate machine setting parameters}

\subsection{Initial machining setting parameters}

After design, nominal pressure angle $\alpha$, mean spiral angle $\beta$, equivalent tooth number $z_{0}$ are unchangeable. As the root line tilted, the sum of dedendum angle will not meet equation (7). The spiral angle varies along the length of the tooth. So a point $m$ is selected to ensure the normal taper and a well meshing performance. The point is named as

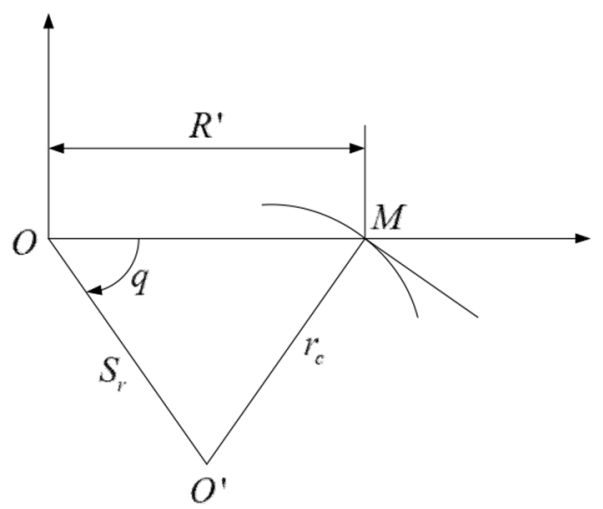

Fig. 3. Installment of cut.

modified mean point can calculated as

$$
R^{\prime}=\frac{r_{c}}{\sin \beta}\left[1-\frac{z_{0} \tan \alpha N_{0}}{540 \tan \beta}\right]
$$

Analysis equation (25), the real cut number $N_{0}$ will affect the position of modified mean point, so the approximate position of contact pattern can be controlled by selecting cut number.

The machine setting parameters are calculated in modified mean point. The installment of cut is shown in Figure 3. The machine center to back and vertical offset are both 0 . Other calculation formulas are shown as follows

The radial setting position is calculated as

$$
S_{r}=\sqrt{r_{0}^{2}+\left(R^{\prime}\right)^{2}-2 r_{c} R^{\prime} \cos \beta}
$$

Initial cradle angle setting is calculated as

$$
q=\arctan \frac{r_{c} \cos \beta}{R^{\prime}-r_{c} \sin \beta}
$$

After the root tilted, machine center to back is changed. The change is determined as

$$
X_{b}=R^{\prime} \tan \left(\Delta \theta_{f}\right)
$$

And other parameters are calculated as

$$
R_{a}=\frac{\cos \theta_{f}}{\sin \delta}
$$

\subsection{Influence of cutter number on pressure angle}

After real cutter number is determined, profile angle can be determined as

$$
\begin{aligned}
& \alpha_{0 \mathrm{e}}=\alpha-\frac{N_{0}}{6} \\
& \alpha_{0 i}=\alpha+\frac{N_{0}}{6}
\end{aligned}
$$


The difference of pressure angle on concave side and convex side in modified mean point is

$$
\Delta \alpha=0.5\left(\tan \theta_{f 1}+\tan \theta_{f 2}\right) \sin \beta
$$

Only spiral angle at modified mean point is considered and varies along the tooth length. So the difference of pressure angle on concave side and convex side in the any point can be expressed

$$
\begin{aligned}
& \sin \beta_{y}=\frac{1}{2 r_{c}}\left(R_{y}+\frac{R^{\prime}\left(2 r_{c} \sin \beta-R^{\prime}\right)}{R_{y}}\right) \\
& \Delta \alpha_{y}=0.5\left(\tan \theta_{f 1}+\tan \theta_{f 2}\right) \sin \beta_{y}
\end{aligned}
$$

Here $\beta_{y}, R_{y}$ is spiral angle and cone distance corresponding to the point respectively.

The difference of pressure angle between modified mean point and any point can be expressed as

$$
\Delta^{\prime} \alpha=\left(\tan \theta_{f 1}+\tan \theta_{f 2}\right)\left(\sin \beta_{y}-\sin \beta\right)
$$

Then equation (33) can be arranged as

$$
\Delta^{\prime} \alpha=\frac{1}{r_{c}}\left(1-\frac{r_{c} \sin \beta}{R^{\prime}}\right)\left(\tan \theta_{f 1}+\tan \theta_{f 2}\right)\left(R_{y}-R^{\prime}\right)
$$

In modified mean point of tooth line $\beta=\beta_{y}$, so $\Delta^{\prime} \alpha=0$. As far away from the modified mean point, the difference of pressure angle becomes large which will affect mesh performance and leads to bias in contact pattern.

\subsection{Influence of helical correction motion on pressure angle}

Helical motion is a modified movement. In addition to generating motion during manufacture, the work piece and cut have a linear motion relation in direction of cradle axis. The helical motion has an effect on correction of pressure angle; the basic principle of the modification is shown in Figure 4.

Generating is composed of the work piece rotation and cut velocity $\mathbf{v}_{t}$ (along the tangent direction of the gear) asposition1 shows, and the pressure angle in mesh point $m_{1}$ is $\alpha_{1}$; considering helical motion (position 2), then a radial motion $\mathbf{v}_{r}$ is added, resultant motion cut can be expressed as $\mathbf{v}$, as shown in Figure 4 . The pressure angle in mesh point $m_{2}$ is $\alpha_{2}$, and $\alpha_{2}=\alpha_{1}+\Delta \alpha$.

The change of pressure angle depends on the ratio of radial velocity $\mathbf{v}_{r}$ and tangential velocity $\mathbf{v}_{t}$

$$
\tan \Delta \alpha=\frac{\mathbf{v}_{r}}{\mathbf{v}_{t}}=\frac{p \cdot \omega}{R^{\prime} \cdot \omega}=\frac{p}{R^{\prime}}
$$

Here, $\omega$ is the rotational angular velocity of cradle; $p$ is the lead of helical motion.

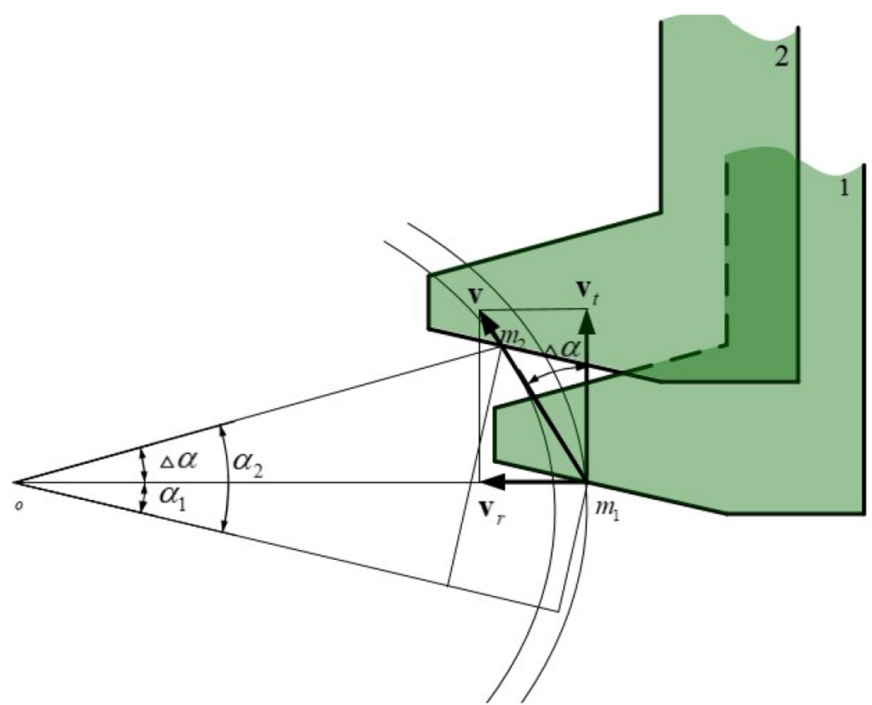

Fig. 4. Influence of helical motion on pressure angle.

The change of pressure angle $\Delta \alpha_{y}$ at any point in tooth line can be expressed as

$$
\tan \Delta \alpha_{y}=\frac{p}{R_{y}}
$$

The change in normal pressure angle can be expressed

$$
\tan \Delta \alpha_{y}=\frac{p \cos \beta_{y}}{R_{y}}=\frac{p \cos \beta_{y}}{R_{y}} \approx \Delta \alpha_{y}
$$

Then in modified mean point

$$
\tan \Delta \alpha=\frac{p \cos \beta}{R} \approx \Delta \alpha
$$

The difference $\Delta^{\prime \prime} \alpha$ between at any point and modified mean point in tooth line can be expressed as

$\Delta^{\prime \prime} \alpha=\Delta \alpha_{y}-\Delta \alpha=p\left(\frac{\cos \beta_{y}}{R_{y}}-\frac{\cos \beta}{R^{\prime}}\right) \approx-\frac{p \cos \beta}{R^{\prime} 2}\left(R_{y}-R^{\prime}\right)$

The difference is proportional to the distance from modified mean point.

If set $\Delta^{\prime} \alpha+\Delta^{\prime \prime} \alpha=0$, the bias in generated by cut number will be eliminated by the difference of pressure angle generated by helical motion. Then the helical motion coefficient can be expressed as

$$
p=\frac{R^{2}}{r_{c} \sin \beta}\left(1-\frac{r_{c}}{R^{\prime}} \sin \beta\right)\left(\tan \theta_{f 1}+\tan \theta_{f 2}\right)
$$

While for some special working conditions, a bias in contact is more suitable. Then coefficient of helical motion can be adjusted to get an ideal contact pattern. 


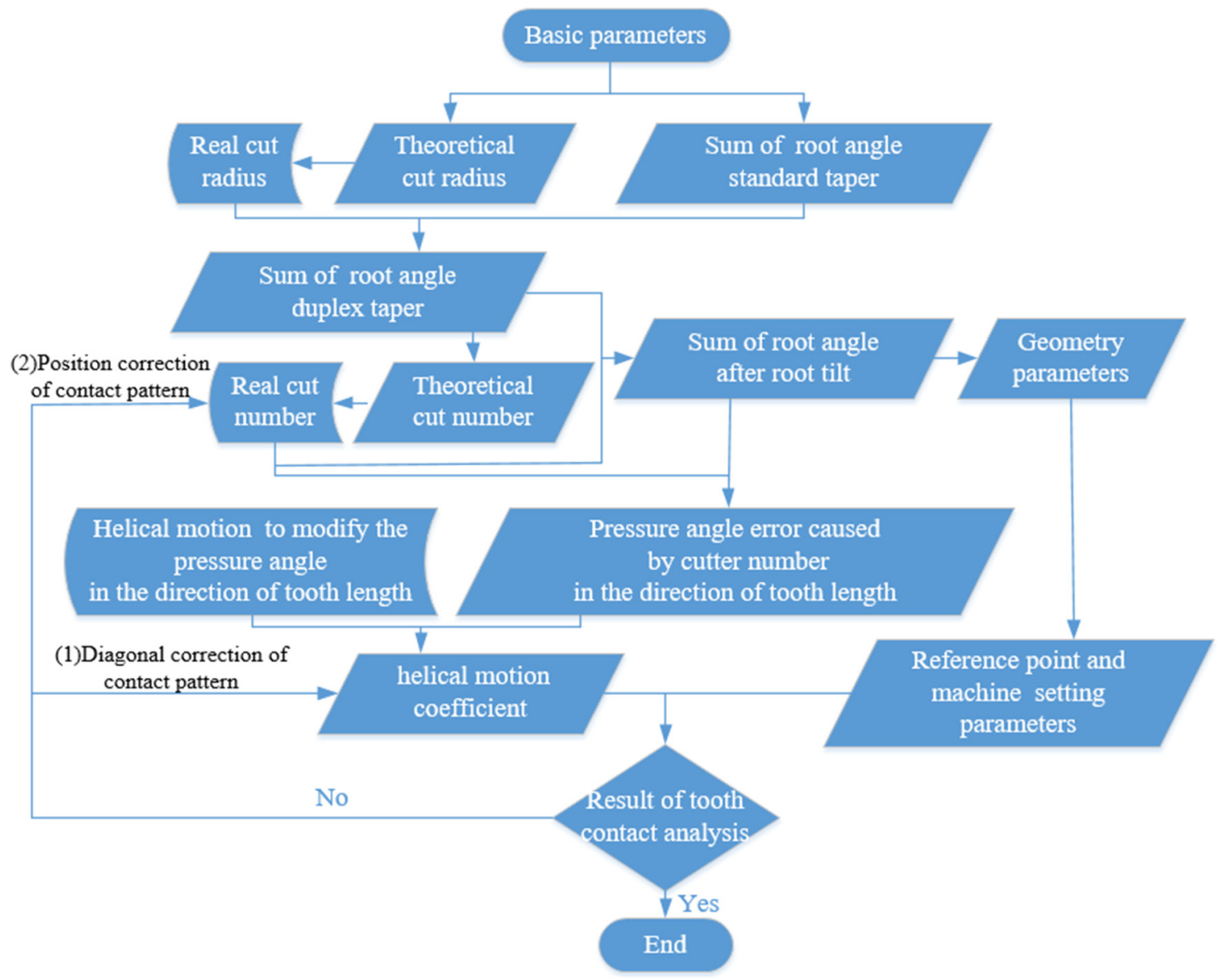

Fig. 5. Flow chart of technological process.

\section{Technological process of double-side milling method}

According to the method proposed in this paper, the flow chart is shown in Figure 5.

As shown in Figure 5, according to basic parameters the sum of dedendum angle in standard taper and a theoretical nominal radius can be calculated. Then the sum of dedendum angle in duplex taper and a theoretical cut number can be obtained. As the real cut number may not equal to theoretical, the sum of dedendum angle is modified by root tilt. After dedendum angle is determined, the geometry parameters can be count. A modified mean point is selected and machine setting parameters is calculated in modified mean point. Only the pressure angle in modified mean point is guaranteed. For cut number a pressure angle error will cause in the direction of tooth length. A helical motion is introduced to modify the pressure angle in the direction of tooth length. Then a tooth contact analysis to check the machine setting parameters. The helical motion coefficient and real cut number are adjusted to optimize contact performance.

\section{Numerical examples}

A pair of spiral bevel gear was taken as an example for experimental verification. The geometric parameters were
Table 1. Geometric parameters.

\begin{tabular}{lll}
\hline & Pinion & Gear \\
\hline Shaft angle $\left(\sum /{ }^{\circ}\right)$ & 90 & \\
Spiral angle $\left(\beta /{ }^{\circ}\right)$ & 35 & \\
Pressure angle $\left(\alpha /{ }^{\circ}\right)$ & 20 & \\
Modulus $\left(m_{\mathrm{t}}\right)$ & 7.16 & \\
Tooth width $(b / \mathrm{mm})$ & 45 & 35 \\
Tooth number $(z)$ & 18 & 64.63 \\
Face angle $\left(\delta_{a} /{ }^{\circ}\right)$ & $31.65^{\circ}$ & 62.783 \\
Pitch angle $\left(\delta /{ }^{\circ}\right)$ & 27.217 & 58.35 \\
Root angle $\left(\delta_{f} /{ }^{\circ}\right)$ & 25.36 & 4.43 \\
Dedendum angle $\left(\delta_{f} /{ }^{\circ}\right)$ & 1.85 & \\
Working depth $\left(h_{w e} / \mathrm{mm}\right)$ & 12.33 & \\
Whole depth $\left(h_{e} / \mathrm{mm}\right)$ & 13.81 & 3.55 \\
Addendum $\left(h_{a e} / \mathrm{mm}\right)$ & 8.78 & 10.26 \\
Addendum $\left(h_{f e} / \mathrm{mm}\right)$ & 5.03 & \\
\hline
\end{tabular}

shown in Table 1, and machine setting parameters were shown in Table 2.

The helical motion coefficient of pinion was set as $-1,0,1$ respectively to calculate the tooth surface. The comparison of tooth surface is shown in Figure 6. Blue is corresponding to pinion theoretical tooth surface, black is the corresponding 
Table 2. Machine setting parameters.

\begin{tabular}{|c|c|c|c|}
\hline \multicolumn{2}{|l|}{ Parameters name } & Pinion & Gear \\
\hline \multicolumn{2}{|c|}{ Radial setting $\left(S_{r} / \mathrm{mm}\right)$} & 103.0815 & 103.0815 \\
\hline \multicolumn{2}{|c|}{ Initial cradle angle setting $\left(q /{ }^{\circ}\right)$} & 65.27172 & 65.27172 \\
\hline \multicolumn{2}{|c|}{ Vertical offset $\left(E_{m} / \mathrm{mm}\right)$} & 0 & 0 \\
\hline \multicolumn{2}{|c|}{ Machine center to back $\left(X_{\mathrm{g}} / \mathrm{mm}\right)$} & 0 & 0 \\
\hline \multicolumn{2}{|c|}{ Sliding base $\left(X_{b} / \mathrm{mm}\right)$} & 0.97 & 0.97 \\
\hline \multicolumn{2}{|l|}{ Machine root angle $\left(\gamma /{ }^{\circ}\right)$} & 24.417 & 58.6 \\
\hline \multicolumn{2}{|l|}{ Roll ratio $\left(R_{a}\right)$} & 2.18519 & 2.18519 \\
\hline \multirow[b]{2}{*}{ Cutter radius $\left(r_{1 i} / \mathrm{mm}\right)$} & Concave side & 115.805 & 115.805 \\
\hline & Convex side & 112.795 & 112.795 \\
\hline \multirow{2}{*}{ Profile angle $\left(\alpha_{1 i} /{ }^{\circ}\right)$} & Concave side & 18 & 18 \\
\hline & Convex side & 22 & 22 \\
\hline
\end{tabular}

Here $i=1$ represents concave side of pinion and $i=2$ represents convex side of pinion.

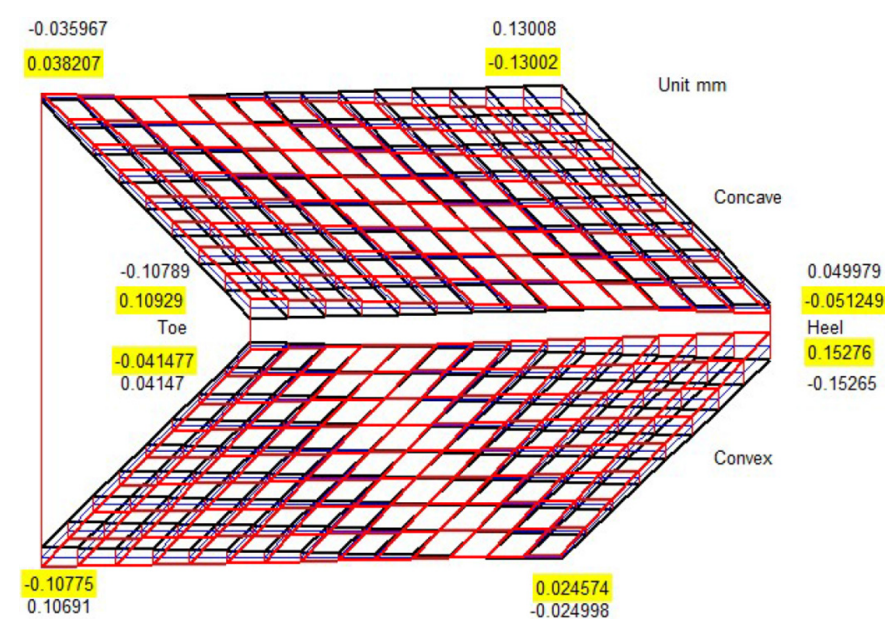

Fig. 6. Influence of helical motion on tooth surface topology.

to $p=1$, and red is the corresponding to $p=-1$.

When $H=1$, for concave side, the correction is $-0.10789 \mathrm{~mm}$ in toe of topland, $-0.035967 \mathrm{~mm}$ in toe of root, $0.049979 \mathrm{~mm}$ in heel of top land, $0.13008 \mathrm{~mm}$ in heel of root; for convex side, the correction is $0.04147 \mathrm{~mm}$ in toe of topland, $0.10691 \mathrm{~mm}$ in toe of root, $-0.15265 \mathrm{~mm}$ in heel of top land, $-0.024998 \mathrm{~mm}$ in heel of root. Compared with theoretical tooth surface, for concave side, the pressure angle become small comparing to theory in toe of top land, and become large in heel of root, while the change of pressure angle are bigger comparing to the change in the direction from toe of root to heel of top land.

When $H=-1$, for concave side, the correction is $0.10929 \mathrm{~mm}$ in toe of topland, $0.038207 \mathrm{~mm}$ in toe of root, $0.038207 \mathrm{~mm}$ in heel of topland, $0.13002 \mathrm{~mm}$ in heel of root; for convex side, the correction is $-0.04147 \mathrm{~mm}$ in toe of topland, $-0.10775 \mathrm{~mm}$ in toe of root, $0.15276 \mathrm{~mm}$ in heel of topland, $0.024574 \mathrm{~mm}$ in heel of root. Compared with theoretical tooth surface, for concave side, the pressure angle become large comparing to theory in toe of topland, and become small in heel of root, while the change of pressure angle are bigger comparing to the change in the direction from toe of topland to heel of root.

Analysis Figure 6, the influence trend of helical motion coefficient on concave side and convex side are opposite, and helical motion coefficient has no effect on modified mean point. As far away from modified mean point, the change of pressure angle is large. Analysis results are consistent with equation (40). So a well performance can be obtained by adjust helical motion coefficient.

Comprehensively considering the contact pattern and transmission error curve, a helical motion coefficient is taken as $p=-0.3$, and the corresponding results of tooth contact analysis (TCA) are shown in the Figure 7.

Finite element analysis is also an effective method to analyze tooth surface contact [15]. Not only can contact moment of the tooth surface under the corresponding load be observed intuitively, contact stress can also be seen by the result of finite element analysis. Firstly 3D model of pair were established based on literature [9]. Then the finite element model was established by preprocess as shown in Figure 8. The results of finite element analysis by Abaqus with a load of $500 \mathrm{~N}$ are shown in the Figure 9.

As Figure 9 shown, (a) is the stress distribution for gear convex side and (b) is the stress distribution for gear concave side. The biggest contact stress is 242.8 and $303.4 \mathrm{MPa}$ under the load of $500 \mathrm{~N}$. The contact pattern is in the middle of tooth surface and there is no edge contact occurs, which is consistent with the results of TCA.

The contact performance is verified by tooth contact analysis and finite element analysis. The method proposed in this paper is proved to be effective in theory.

\subsection{Simulation}

According to the parameters listed in Table 2, a cut model was built as shown in Figure 10. Simulation by VERICUT is carried out to check and debug processing procedures. The simulate process and product of pinion are shown in 

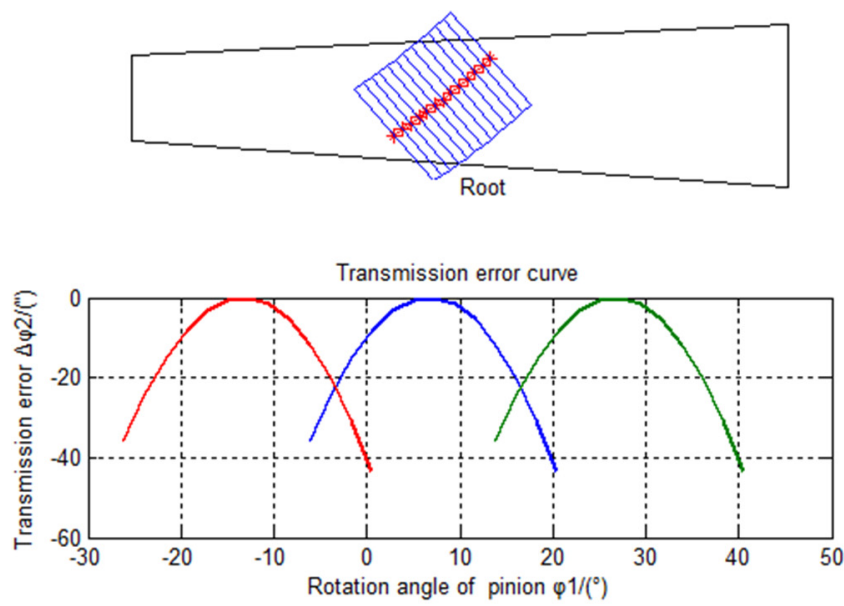

(a)
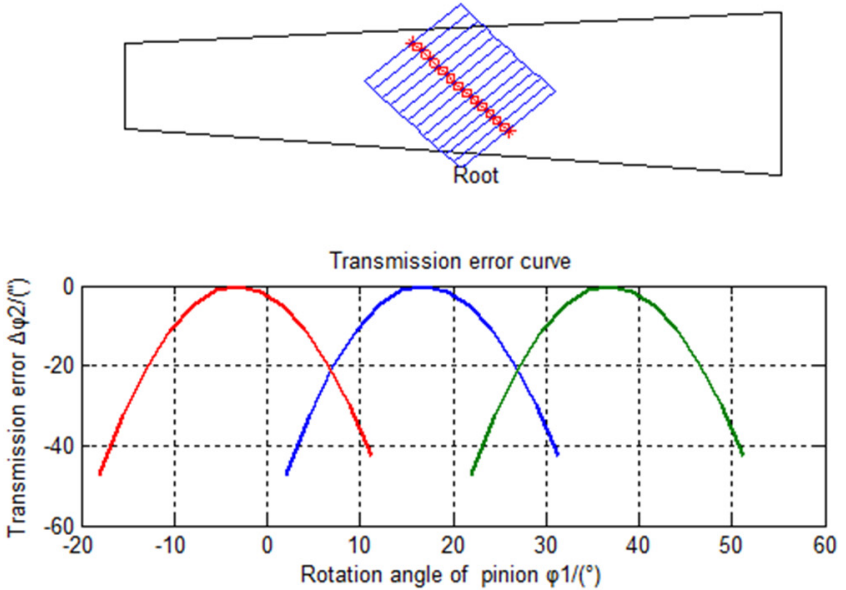

(b)

Fig. 7. Result of TCA. (a) Convex side. (b) Concave side.

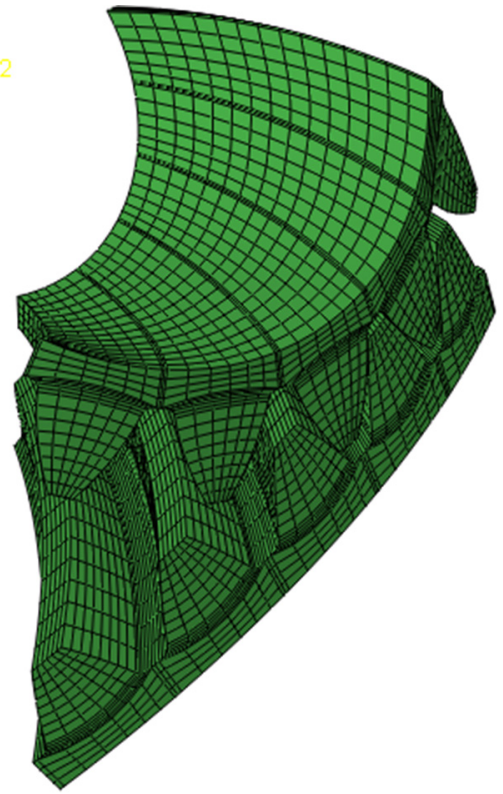

Fig. 8. Model of finite element analysis.

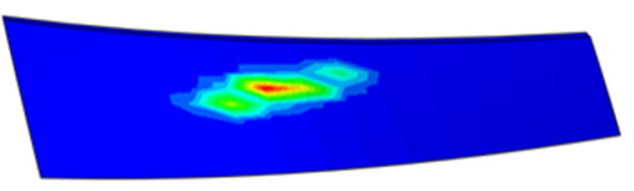

(a)

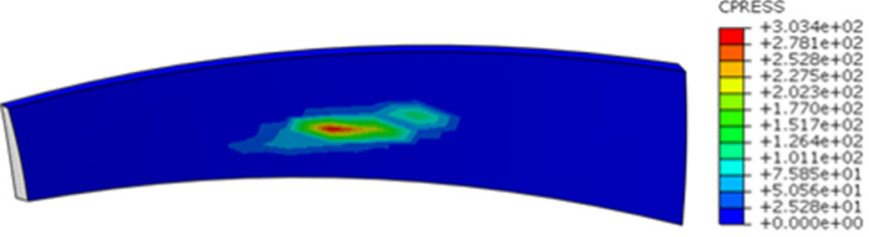

(b)

Fig. 9. Results of finite element analysis. (a) Convex side of gear. (b) Concave side of gear.

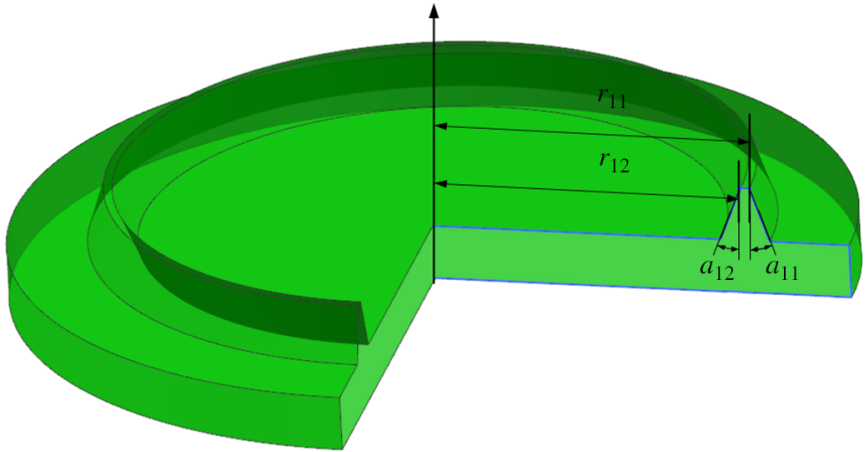

Fig. 10. Model of cutter.

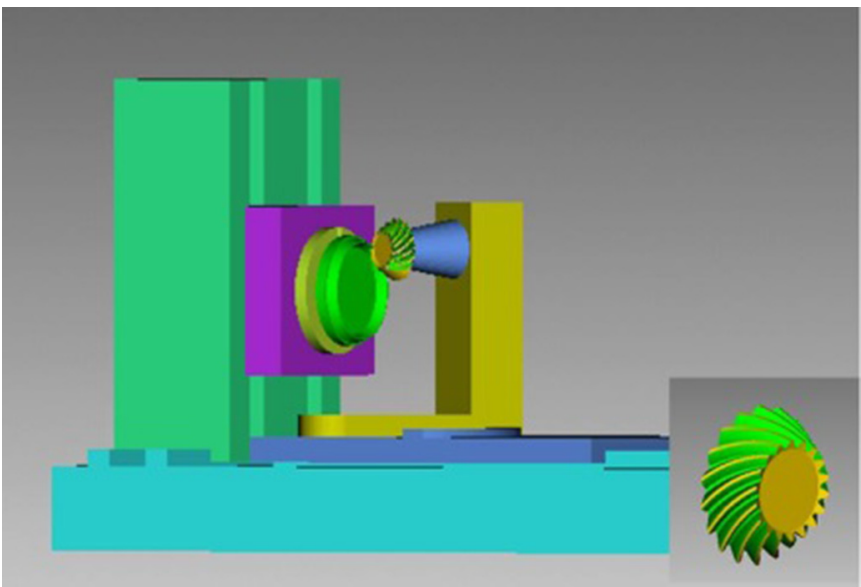

Fig. 11. Simulation process and product.

Figure 11. A comparison between simulation product with theoretical was done and the results are shown in Figure 12. Only pinion process is simulated.

As the results showed in Figure 12, the simulated product and established model are basically the same. In tooth surface, the biggest error in tooth surface is $0.02 \mathrm{~mm}$ for concave side and convex side. While the main error is in 
the root, the overcut and residue error is $0.05 \mathrm{~mm}$. The tooth surface error comes from automatic approximated of parameters during model establishment for the precision of parameters are reserved to three decimal places or even more. The error in root mainly comes from the error caused by approximation of machine root angle. The comparison error meet engineering requirement. The correctness of parameters and machining procedures are verified.

\subsection{Cutting experiment}

The tooth cutting experiment was carried out on YK2260X which is a five-axis four linkage CNC milling machine developed by LUOYANG KEDA YUEGE CNC MACHINETOOL Co., LTD. The workpieces were installed

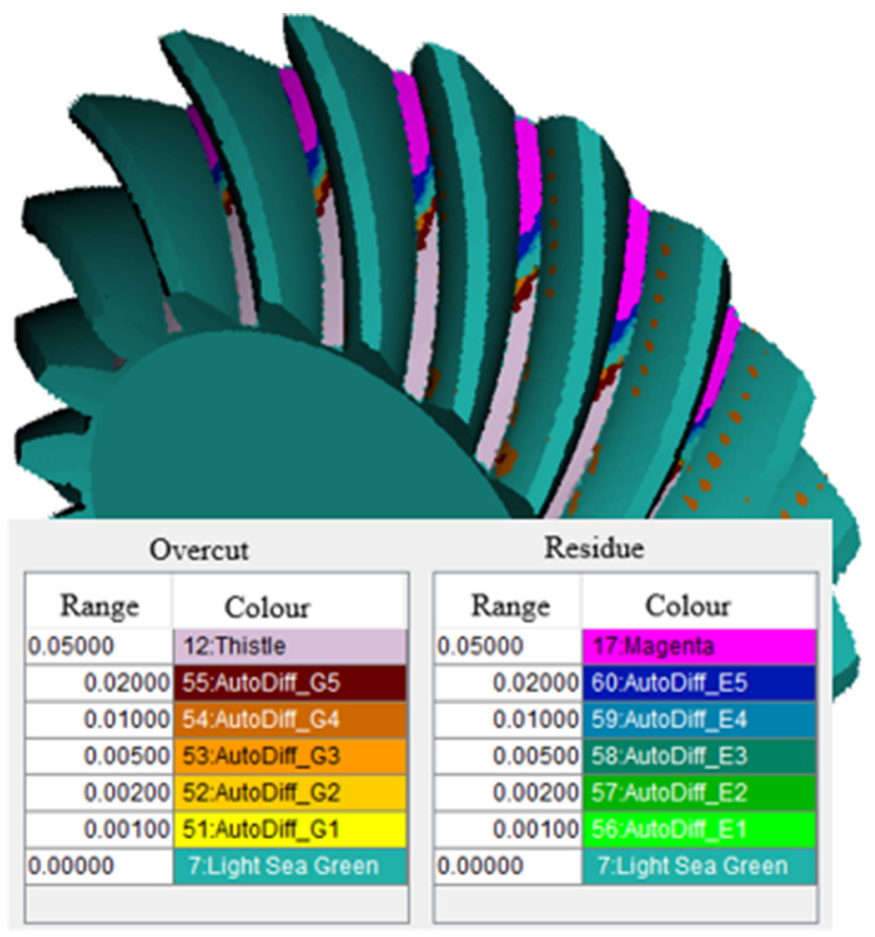

Fig. 12. Results of comparison.

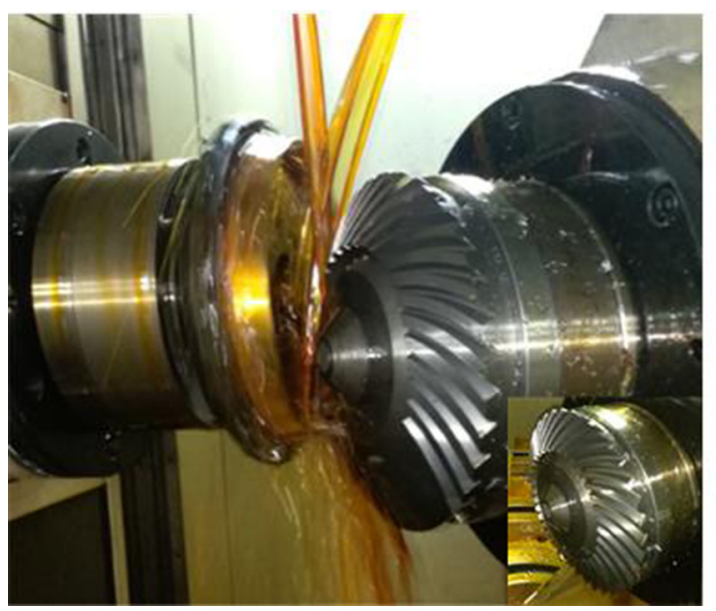

(a) in $0.01 \mathrm{~mm}$ of diameter runout and face runout. No tremor during the cutting process. The scenes of tooth cutting are shown in Figure 13.

In order to check quality of process tooth surface, pinion and gear were measured after chamfering, burring and cleaning. The scenes of tooth surface measurement are shown in Figure 14. The results of measurement are shown in Figure 15.

As shown in Figure 14, (a) is the scene of gear process and $(\mathrm{b})$ is the scene of pinion process. Figure $15 \mathrm{a}$ and $\mathrm{b}$ is the measurement results of gear and pinion, respectively. For gear measurement as displayed in Figure 15a, the biggest tooth surface error of gear is 0.004 and $0.006 \mathrm{~mm}$ for convex side and concave side. For pinion measurement as displayed in Figure 15b, the biggest tooth surface error of gear is 0.006 and $0.004 \mathrm{~mm}$ for convex side and concave side. The errors meet the engineering requirement and have little influence on the meshing performance of tooth surface.

Finally a rolling test was carried out. The workpieces were installed in $0.01 \mathrm{~mm}$ of diameter runout and face runout. The rolling ran smoothly without obvious vibration noise. The results were shown in Figure 16.

As Figure 16 shows, (a) is the scene of rolling test, (b) is tooth contact pattern of gear convex side, and (c) is tooth contact pattern of gear concave side. The contact pattern is located in the middle of the tooth surface and there is no edge contact and other bad contacts. The rolling test results are basically consistent with Figures 7 and 9 in position and shape. The results of experiment prove that the method proposed in this paper is effective and feasible.

\section{Conclusions}

Different from the traditional method of calculating geometric parameters by transverse module in heel, the double-side geometric parameter design of spiral bevel gear is completed by normal module in mean cone distance combined with the cut parameters.

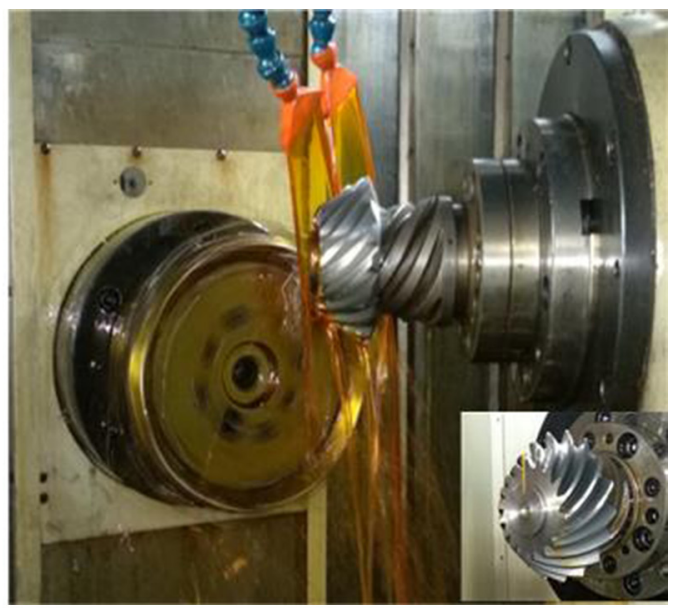

(b)

Fig. 13. Cutting experiment. (a) Gear. (b) Pinion. 


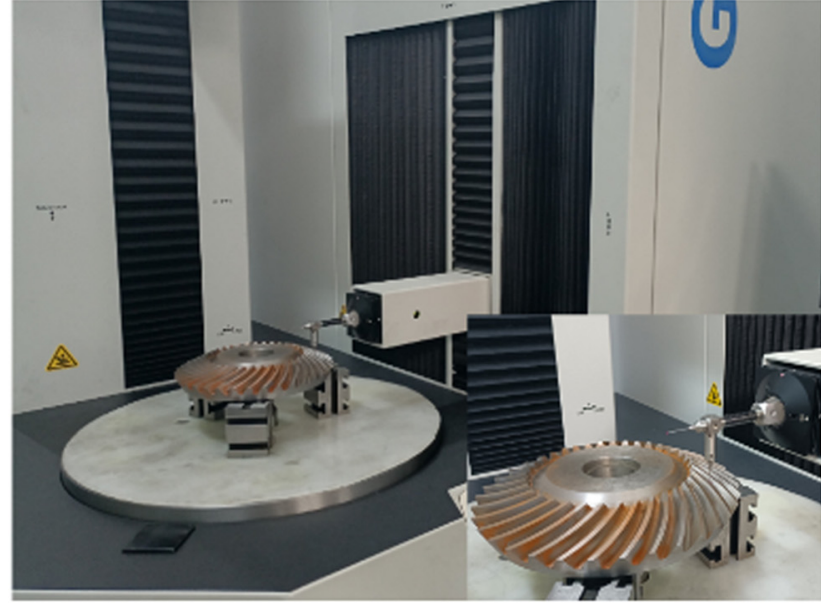

(a)

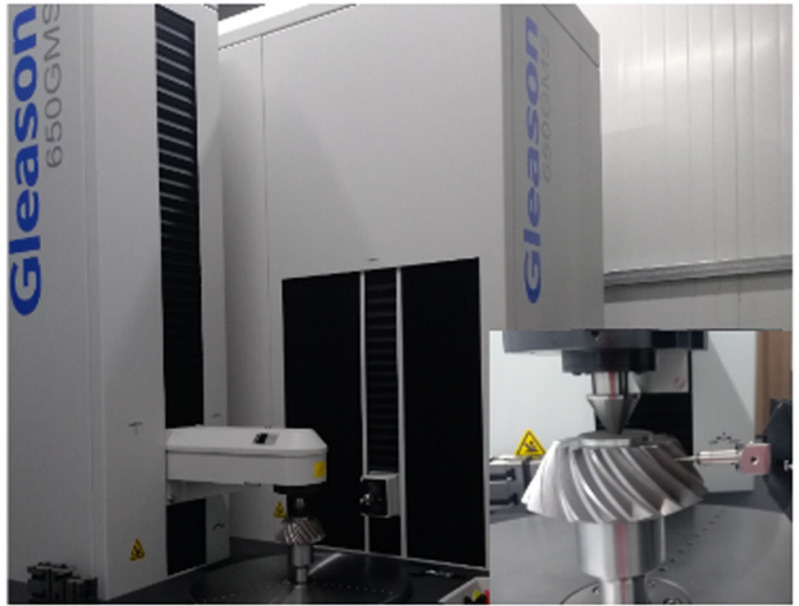

(b)

Fig. 14. Scene of measurement. (a) Gear. (b) Pinion.

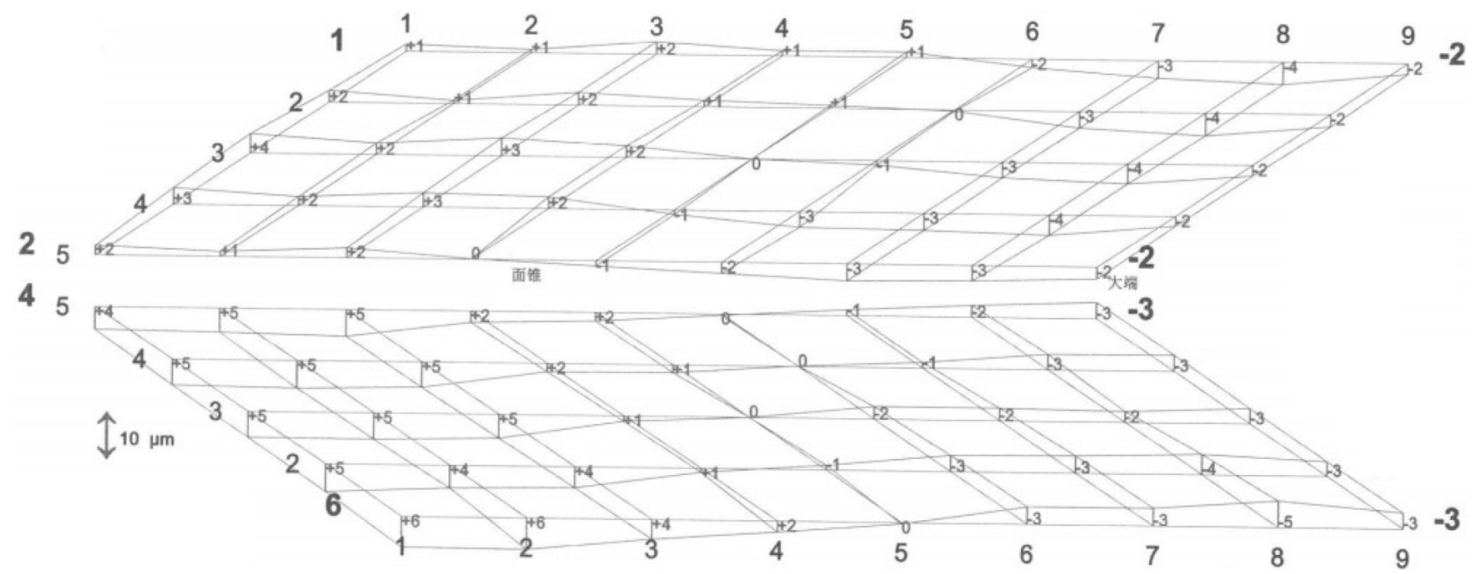

(a)

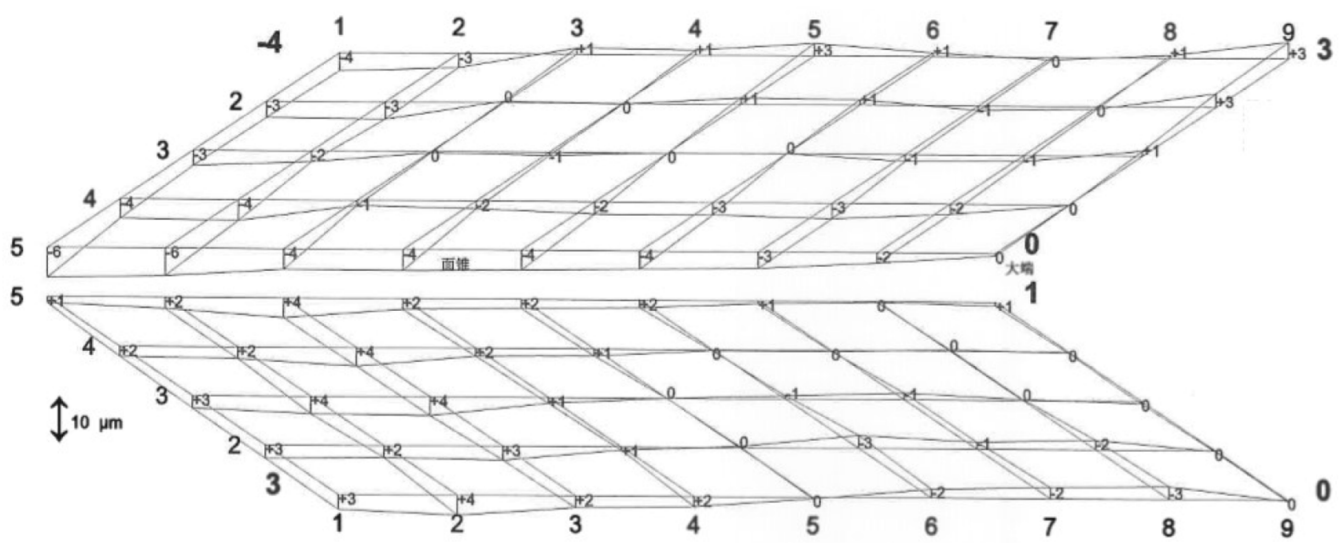

(b)

Fig. 15. Measurement results of tooth surface. (a) Gear. (b) Pinion.

According to taper of double-side method, a point named modified mean point meet meshing condition is calculated, and the machining setting parameters in modified cone distance are calculated.
The effect of cutter number on the pressure angle in the direction of the tooth length is analyzed. And the influence of helical motion coefficient on tooth surface is researched. The results show that the helical motion can correct 


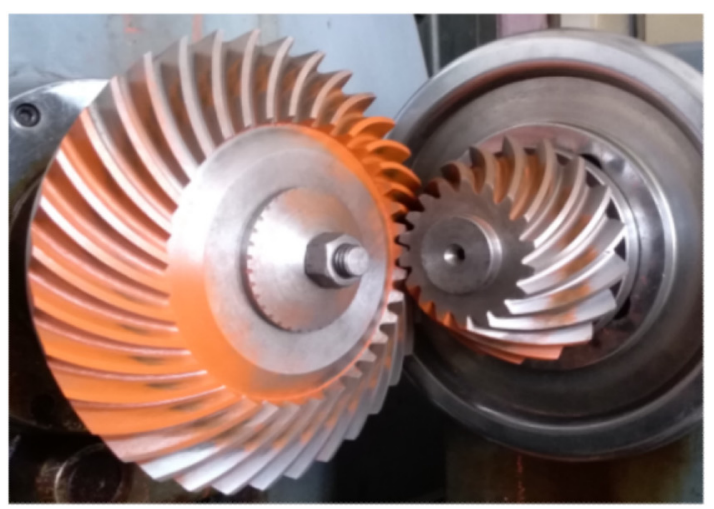

(a)

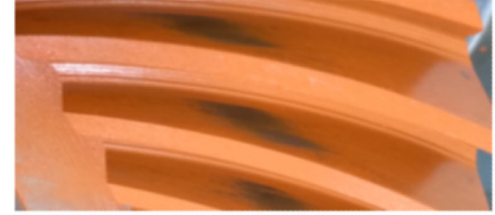

(b)

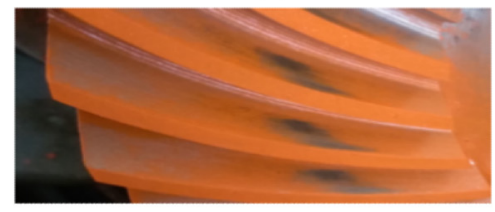

(c)

Fig. 16. Rolling test and results. (a) Rolling test. (b) Convex side of gear. (c) Concave side of gear.

the pressure angle in the direction of tooth length. The optimizing of contact performance by adjusting the helical motion coefficient is realized.

The experimental results are consistent with the theoretical analysis results, which verify the effectiveness and feasibility of the double-side machining of spiral bevel gears proposed in this paper.

The authors would like to thank the financial aid and support from the National Natural Science Foundation of China (Grant NO. 51975185, Grant NO. 52005157, and Grant NO. 51475141), the Major science and technology projects of Henan Province (Grant NO. 191110213300-05), and the National key Research and development program (Grant NO. 2020YFB1713505-4). We are grateful to the reviewers and editors for their valuable comments and suggestions.

\section{References}

[1] F.L. Litvin, A. Fuentes, K. Hayasaka, Design, manufacture, stress analysis, and experimental tests of low-noise high endurance spiral bevel gears, Mech. Mach. Theory 41, 83-118 (2006)

[2] H.J. Stadtfeld, Tribology aspects in angular transmission systems part IV: spiral bevel gears, Gear Technology 66-72 (2011)

[3] F.L. Litvin, Y. Zhang, M. Lundy, C. Heine, Determination of settings of a tilted head cutter for generation of hypoid and spiral bevel gears, ASME J. Mech. Transm. Autom. Des. 110, 495-500 (1988)

[4] B.A. Shtipelman, Design and Manufacture of Hypoid Gears, Wiley, New York, 1978

[5] F.L. Litvin, A. Fuentes, Gear Geometry and Applied Theory, 2nd edition, Cambridge University Press, New York, 2004
[6] F.L. Litvin, Y. Zhang, Local synthesis and tooth contact analysis of face-milled spiral bevel gears, Technical Report National Aeronautics and Space Administration, Cleveland, 1991

[7] Beijing Gear Factory, Spiral Bevel Gear 1974, Science Press (in Chinese)

[8] K. Kawasaki, H. Tamura, Duplex spread blade method for cutting hypoid gears with modified tooth surface, J. Mech. Des. 120, 441-447 (1998)

[9] L.L. Geng, X.Z. Deng, X.M. Cao et al., Research on calculation of machine-tool settings and flank modification for spiral bevel gear by duplex spread blade method based on 4-axis CNC milling machine, J. Adv. Mech. Des. Syst. Manuf., 14, 1-16 (2020)

[10] Gleason Works, Calculation Instructions Generated Hypoid Gears Duplex Helical Method, The Gleason Works, New York, 1971

[11] C.B. Tsay, J.Y. Lin, A mathematical model for the tooth geometry of hypoid gears, Manuf. Compu. Model. 18, 23-34 (1993)

[12] A. Gonzalez-Perez, A. Fuentes, K. Hayasaka, Computerized design and tooth contact analysis of spiral bevel gears generated by the duplex helical method, in: ASME 2011 International Design Engineering Technical Conferences and Computers and Information in Engineering Conference, American Society of Mechanical Engineers, Washington, DC, United states, 2011, pp. 149-158

[13] Y. Zhang, H.Z. Yan, New methodology for determining basic machine settings of spiral bevel and hypoid gears manufactured by duplex helical method, Mech. Mach. Theory 100, 283-295 (2016)

[14] Y. Zhang, H.Z. Yan, T. Zeng, Cutting principle and tooth contact analysis of spiral bevel and hypoid gears generated by duplex helical method, J. Mech. Eng. 51, 15-23 (2015)

[15] S. Bodzás, Designing and analysis of the TCA parameters of a bevel gear having circular tooth direction in the function of the moment, J. Appl. Polym. Sei. Eng. 6, 310-328 (2019)

Cite this article as: L. Geng, X. Deng, H. Zhang, S. Nie, C. Jiang, Theory and experimental research on spiral bevel gear by double-side milling method, Mechanics \& Industry 22, 33 (2021) 